\title{
The Memory-History-Popular Culture Nexus: Pearl Harbor As a Case Study in Consumer-Driven Collective Memory
}

\author{
by Patricia Leavy \\ Stonehill College \\ Sociological Research Online, Volume 10, Issue 1, \\ < http://www.socresonline.org.uk/10/1/leavy.htm/> \\ doi:10.5153/sro. 1021
}

Received: 7 Nov 2003 Accepted: 8 Mar 2005 Published: 31 Mar 2005

\begin{abstract}
In this paper I examine the fusing of collective memory, history and popular culture by analyzing current trends in American-made commercial films with historical events as subject matter that have also been distributed to a global audience. Pearl Harbor is the primary case study. Analysis shows that dominant historical narratives are reified by the use of what I term an 'anticipatory-driven' film experience where audience members engage in an interaction with pre-existing mainstream collective memory while their anticipation for impending climactic trauma is systematically heightened. Comparisons are made to other widely released US films about national and international events and 'non-events.' Questions are also raised about the increasing global importance of the memory-history-popular culture nexus post 9-11, and, how US produced films about 9-11 may or may not engage in the practices detailed in this analysis. In this vein the paper concludes with a discussion of how Pearl Harbor was marketed, edited and received in Japan, the second largest audience for Hollywood films and what this implies about social memory construction in a global commercial context.
\end{abstract}

\section{Keywords: Collective Memory, Film, Hollywood, National Identity, Pearl Harbor, Social Memory}

\section{Introduction}

1.1 In a global context increasingly inundated with mass-mediated representations of events labeled newsworthy, what is the relationship between collective memory, history and popular culture? Specifically, how does the American film industry construct images of traumatic events specific to the US and those shared with other nations? Moreover, how are these films and associated products distributed and consumed by a global audience? Using the example of Pearl Harbor these are some of the questions raised in this paper. Through an analysis of the film Pearl Harbor, and comparisons to other Americanmade films with historical event-based content I examine the fusing of memory, history and popular culture and raise social questions about the meaning of this nexus in a global context post-9-11. How the US represents its own shared history- within largely fictive fields-has become increasingly important. Furthermore, the representations central to this process are available for inquiry both locally and globally making any new patterned phenomena ripe for critical investigation.

1.2 Collective memory is a space where culture fuses with social power resulting in a dominant, although contested, historical narrative. "Cultural memory" is a site of negotiation that is intimately tied to national identity formation (Sturken 1997). Conceptualizing historical knowledge as the product of collective memory articulates the social power involved in writing history, the conflicts over meaning that arise during the process, and the partiality of dominant historical narratives. Remembered history isn't "historical fact" (in a traditional sense) but rather the result of contentious memory practices. Foucault (1975) asserts that memory is a site of possible resistance. History is the past as it was written, imaged and consumed in the present-moment through culturally specific commemorative rituals. The intimate relationship between American social history and American collective memory radically changed with the coming of the printing press as these formerly distinguishable concepts began to visibly overlap. This phenomenon is again in a critical period of transformation due to the mass media.

1.3 Within our hypermodern context the blurring of collective memory and history is primarily articulated in the realm of commercialized popular culture. While commercialized popular culture is hardly new, the form 
in which history-memory operates in this realm is clearly a recent hypermodern form and accordingly in need of critical interrogation. Representations within popular culture reflect this relationship and contain tensions and historically specific conflicts over meaning. Memory-representations are the material emblems of historically situated processes of knowledge construction. Exercises of social power within this realm rely on the reconstruction, circulation and consumption of social-historical memory and can be explicitly seen through an examination of appropriate cultural artifacts. By social historical memory I mean that memory products are necessarily situated within a social context-a context that embodies aspects of the social environment in which the historical event originally occurred and the political-cultural economy in which the memory artifact, perhaps years or decades later, was produced. Films are a common medium for circulating historical narratives within media culture.
"Filmed 'memories', according to a national survey in the United States on Popular sources and uses of the past by Americans, now form an important part of how we learn history: Eighty per cent of respondents said they had recently watched movies or television programmes about the past, in comparison with 53 per cent who said they had read a book about the past (Rosenweig and Thelen, 1999: 15-6)... Film was said to make events 'more Real'..." (Reading, 2002: 77-8)

1.4 Hollywood is dominant within world cinema (Grainge, 2003:3) making American's cinematic portrayal of its shared history globally significant.
"Hollywood has functioned strategically in the articulation and codification of the cultural past." (Grainge, 2003:4)

Narrative films and associated off-shoot commodity forms together represent the hypermodern transmission of collective memory and the changing landscape of commercialized popular culture. In this essay I am interested in how historical events are narrated within this changing terrain.

\begin{abstract}
1.5 In this article I analyze the American 2001 film Pearl Harbor, now circulating worldwide on video and DVD, as a vehicle for collective memory-making. This analysis is situated within a discussion of the relationship between history and collective memory. Once the history-memory matrix is established a connection between history, memory and popular culture is formulated. The recent surge in commodity forms linked to pop culture representations creates a new nexus of memory-making power. Pearl Harbor then takes its place as an example of the history-memory-popular culture nexus that characterizes American social-historical representation within an increasingly global context. A textual analysis of the film Pearl Harbor and its related cultural artifacts is conducted in order to explicate this phenomenon. In this vein, I assess both the form and content of this specific piece of cultural representation by employing a deconstructionist method of textual analysis largely influenced by poststructuralist thought. Pearl Harborthe event, has already served as the subject of interdisciplinary studies in collective memory making the American film purported to "accurately" represent the event particularly appropriate for critical investigation. I conclude by analyzing how the film was marketed and edited for Japanese audiences.
\end{abstract}

\title{
The Fusion of History and Collective Memories
}

2.1 Collective memory, articulated in cultural forms, is the result of social processes. Schudson (1992) defines collective memory as "social memory, referring to the ways in which group, institutional, and cultural recollections of the past shape people's actions in the present (3)." Collective memory can be conceived of as a repository of shared cultural images, narratives and visions of the past. The term "shared" does not indicate consensus because collective memory is a common site of social tensions and political conflicts over meaning (Irwin-Zarecka, 1994). Rather, "shared" implies that these narratives of memory permeate a given society and constitute a dominant discourse about the past. Memory is a political force and a site of opposition (Foucault 1975). Dominant and resistive visions of the past often operate in conjunction with each other and/or in tension with each other although dominant forms monopolize the cultural landscape. This indicates that collective memory is not stagnant but can be revised and contested (Hutton, 1993). It also implies that in the age of the corporate mass media access to channels of mass communication dictate how widely disseminated particular versions of history will be. In a global context it is equally important, glaringly since 9-11, to look at where dominant collective memories about shared historical experiences, are created, and, to whom, globally they are disseminated. While the Internet has provided resistive groups a virtual host through which to reach large audiences, access to the varied instruments which (w)rite history remains highly limited within the US, and, to the US. This is strikingly clear in the case of films and product-based commodities where Hollywood dominates.

2.2 Rituals of collective memory are a normal and even mundane component of every society. They are a part of the daily interpretive processes humans participate in so that they can make sense of the social world. In order to understand the present, individuals contextualize the present-moment with explicit 
reference to the past and implicit reference to the future. The present, and our place within in, is understood and experienced relationally. In this way, all points in time are on a continuum and the present is lived both temporally and spatially. In order to facilitate the contextualization of the present, the past is actively remembered through commemorative practices. These rituals of collective memory crystallize discourses and multi-medium narratives about the past. Commemorative rituals are a form of knowledge construction occurring within a larger web of complex power relations. While collective memory has a relationship with history, the two concepts have not always been interchangeable. Today it is clear that memory has a history and history is (effectively) memory (Hutton, 1993:1).

2.3 Patrick Hutton (1993) argues that during print culture history became irrevocably blurred with collective memory. Technologies of print culture allowed for high-speed dissemination, reproduction and repetition of temporally ordered knowledge. Print culture both textualized and contextualized social memory by creating chronological "records" not only available, but also intended for future inspection (Hutton, 1993:19). Acts of memory in the present created "records" then taken as history in the future, or at least the dominant historical narrative. The historicizing of social memory also transformed history into a commodity. The news was to be packaged as all other commodities. Newsmakers are thus at the forefront of packaging and selling collective memory. In Schudson's language, there are "memory professions" and a "memory industry" (1992:211) which have a large stake in constructing "successful" collective memories.

2.4 Hutton (1993:19) and Iwona Irwin-Zarecka (1994) show that it was during print culture that "events" became the primary material of memory practices. Events present a locus through which a society can represent and interpret itself (Schudson 1992). While the technologies of reproduction are a significant factor in this shift to using events, there are two additional factors to consider: 1) the authority/legitimacy of the press, and, 2) the commercialization of the news for profit.

2.5 Barbie Zelizer (1992) explains that journalists have a special stake in using events as markers of collective memory. Central players in the creation of collective memory, journalists assert their authority over history by determining what is socially significant and then constructing themselves as the objective authorities over what they deem newsworthy. "Critical incidents" and events are thus a tremendous opportunity for the press to assert their own legitimacy (191). Events also allow journalists to negotiate the boundaries of their authority (191). Events are a vital vehicle through which journalists authenticate themselves as the legitimate interpretive community (9) through the canonization of significant moments in history (13).

2.6 What drives collective memory practices in this context? The selection of material to serve as the basis for rituals of memory is based on its perceived commercial value (Irwin-Zarecka, 1994:169) and journalistic value (Zelizer 1992). So with commercialism and journalistic authority as the contexts in which memory is made, what kinds of events become markers? The events immortalized are presented as socially significant and not merely sentimental (Irwin-Zarecka, 1994:171) though this happens largely through a process of "rhetorical legitimacy" in Weber's terms. Arthur G. Neal (1998) explains that events categorized as "national traumas" are likely vehicles for memory practices. What such events have in common is the specific form of "newsworthiness" they invite: they are social disruptions (1998:7-13). Traumatic events create varied degrees of collective grief, collective anger, collective sadness, and collective fear, making them, in Neal's estimation, particularly prone to being the elongated subject of memory practices. Neal includes Pearl Harbor amongst the American events of the past century that underwent severe memory practices for these reasons (1998:70). The selection of "traumatic" events will be explored further as we consider the shift from print to media culture.

\section{The History-Memory-Popular Culture Nexus: Media, Scripts and Commodities}

3.1 The latest transition in rituals of collective memory built upon the history-memory matrix established during print culture. Collective memory now operates within media culture. Hypermodern collective memory within media culture combines the main tenets of ancient mnemonics (image-based memory) and modern print culture while also applying advanced technologies of mass transmission. Collective memories are created and circulate in popular culture constituting a new mode of social power and knowledge building dependent on access to the high-capital (re)construction technologies of this virtual terrain made particularly complex in a world webbed together electronically.

3.2 With the development of the mass media rituals of collective memory center on the (re)production, distribution and consumption of popular representations. These representations are increasingly imagebased and occur in textual, visual, audio-visual and commodity forms. The journalistic and commercial value of significant events is heightened in the media age which links back to the selection of traumatic events as vehicles of collective memory.

3.3 "Traumatic" events, such as Pearl Harbor and September 11th have both journalistic and commercial 
value which in the media age, are inextricably linked. This phenomenon is largely due to the "scripts" or "frames" that the press use as narrative tools- a process which gives journalists the authority to spin their version of historical events with legitimacy while creating a base-line narrative ripe for commercial appropriation.

3.4 Binder (1993) shows that media writers appropriate certain frames in order to make their stories convincing and compelling in ways that capture the audience's imagination in an age when people are bombarded with multi-media stimuli wing for their attention. Cruz (2000) refers to the use of "dominant rhetorical frames" in the maintenance of political power. Ultimately, journalists attempt to tell a story that resonates with cultural beliefs (Binder 1993). But journalists use these "frames" selectively allowing them to focus on particular aspects of a story and thereby construct a particular event narrative (Schudson 1992). The fact that perceptions of audience directly impact the frames journalists choose to use is sociologically significant. Because journalists use resonant frames, which will then legitimate their versions of events because audiences are more likely to absorb them, cultural beliefs guide narrative construction. With this said, the reporting of an event, such as Pearl Harbor or 9-11, differs in different contexts. For example, in the case of 9-11 and the later US-led military actions in Afhanistan and Iraq, there has been a cross-cultiral discussion of which media system is "more accurate"-the US media with its claims of objectivity and neutrality or the Middle East media with its focus on the human toll. In other words, when looking at the frames Al Jezeera and CNN use to narrate 9-11 and the events after, one must consider that journalists are choosing frames they believe will resonate with the citizens of their country. When examining the frames the American journalists employed when narrating Pearl Harbor, they were using frames they assumed would be plausible to the American people.

3.5 In addition to resonant frames, as Gamson \& Modigliani (1989) show, "referent images" are frequently invoked as metaphors through which to frame the social meaning of an event. Sontag (2003) proposes that ideology driven images are the "visual equivalent of sound bites (86)." The flag-raising at Ground Zero after 9-11, with its symbolic value linked to the flag raising at Iwo Jima, is an example of how referent images are used as an interpretive lens and "sound bite." Hoskins (2004) goes even further by arguing that the media itself is a "framework" of memory (110).

3.6 By relying on scripts that resonate with audiences, the press primes their audience to consume their event narrative. This process allows for the legitimating of their authority, or expertise, over events they've deemed important. But these resonant scripts also pave the way for commercial appropriations. The saturation coverage that immediately accompanies media events appears as "cinematic footage", such as in the case of the looping 9-11 footage of the planes hitting the towers followed by their destruction (Hoskins, 2004: 116). Furthermore, the scripts through which these events are represented are generally hero-villain narratives which are easily translated into popular representations, such as film. The use of heroic and villainous "characters" when mapping out the "plot" of a historic event is a widespread phenomenon. In his classic work The Image: A Guide to Pseudo Events in America Boorstin $(1961,1992)$ showed how "pseudo-events" rely on the use of heroic figures because they are compelling to their audience. Pseudo-events are created entirely by the media-such as press conferences. While events such as Pearl Harbor and 9-11 are authentic events in need of interpretation, the press nonetheless uses similar narrative frames. Dayan and Katz (1992) show a similar narrative frame in their study of "media events." Dayan and Katz show that media events always have "heroic figures (12)" and focus on the "neo-romantic desire for heroic action by great men (21)." While they were focusing on pre-planned events that dominate the media through monopolistic coverage, such as presidential parades or televised celebrity funerals, again the same scripts are often employed in the case of authentic events. These hero-driven narratives are quite literally the stuff that commercial television and film are made of, indicating a commercial viability connected to these kinds of stories. This becomes obvious when looking at how Pearl Harbor was received by Japanese audiences.

3.7 Beyond facilitating the application of some narrative scripts over others, the production of collective memory within the realm of popular culture changes the personal and group experience of historical memory in several significant ways. First, by encapsulating social experience in representations, memory is placed exterior to the individual through a host of images (Hutton, 1993:21). Second, history is decontextualized. This is because in the media age there is a return to the spatial configuration of historical narratives as opposed to the temporal patterning that dominated during print culture. Images can float within the popular culture landscape void from chronological grounding. Images can also be reconfigured and textualized according to present need versus original historical location (Hutton, 1993:3). What is most interesting about the return to a spatially conceived configuration of knowledge is that it is occurring at a time when the technology to construct knowledge temporally exists. We have entered a unique historical moment where knowledge is at once both spatial and temporal. Third, the consumption of historical memory now involves anticipation and recollection (Hutton, 1993:23). In addition to, and as a result of, the repetition that characterizes mass-mediated representation, consumers of collective historical memory are 
now anticipating audiences. They actively participate in the recollection of particular historical visions through consciously or otherwise remembering a foundation of free-floating previously consumed images. In other words, when people attend a narrative film about an event that has undergone intense memory practices, the audience "sits at the edge of their seats" anticipating the re-enactment of images and the like that are dominant in the memory of the event. For example, one can imagine that if a commercial film was made about September 11th audiences would expect to see a re-enactment of the planes hitting the towers but also other "moments" such as firefighters carrying away their chaplain and the flag-raising. This anticipatory phenomenon is evidenced during the analysis of Pearl Harbor. But to say that memory practices produce free floating image-driven narratives, that are themselves commodities, only takes us so far. What radically distinguishes this period from previous times is the larger commodity phenomenon associated with pop culture forms that constitutes hypermodern social power.

3.8 Collective memory in the media age directly links history with commercial culture (Lipsitz, 1990:5). During leisure time activities within the realm of commercialized popular culture US citizens of the media age consume social histories. This process has turned history into a commodity aesthetically designed for sale which Americans then re-sell to the rest of the world. Furthermore, this form of carefully packaged fragmented history floats freely in the realm of commercial culture where many citizens spend their leisure time. As the major hosts of historical narratives are television, film, and billboard screens, consumers of collective memory often participate in the reconstruction/recollection of historical memory during what they believe is "escape" time (Lipsitz, 1990:18). In other words, as Americans watch Pearl Harbor they simultaneously are engaged in the reconstruction of their national collective memory while the makers of the film profit. As discussed in more detail in the conclusion, as Pearl Harbor reaches global audiences through cinema showings and DVD and VHS sales, citizens of the world are participating in the reconstruction of an American-centered version of an international event, but in a complex way. This is illuminated later when examining the distribution techniques used when releasing Pearl Harbor in Japan.

3.9 In addition to the (re)construction of social memory within the popular leisure realm, a new strain of filmcommodities has recently emerged in the United States which intimately effects the production of these commodities in the Third World and later exportation to the industrial world. There is a history in the US of selling products in association with commercial films; however, this has traditionally occurred within a specific genre of fictional movies. Specifically, toys, posters and collectables have been produced and sold in conjunction with children's films and action films. The Walt Disney Empire is largely based on the relationship between pop cinematic forms and commodities. While this is a sociologically important component of commercial culture, it has little to do with practices of collective memory and national identity. Over the past few years, commodities have been produced and sold in conjunction with the release of narrative films containing event-based historical subject matter (such as Titanic). These commodity forms are products of memory-practices and constituent components of collective memory, or, the dominant historical narrative. This is the history-memory-popular culture nexus- a hypermodern nexus that constitutes a new form of social power central to the making of memory-history.

\section{Methodology}

4.1 Prior to presenting my analysis it is important to explain my theoretical positioning. Building on some tenets of post-structuralism I apply a deconstructive approach to interpretation and analysis in order to disentangle the dominant story told through Pearl Harbor thereby shedding light on the power-based exclusions within this retelling. Michel Foucault's (1978) work has illustrated the inextricable relationship between social power and knowledge production, implying that all knowledge is produced within historically specific cultural systems. In this tradition Jacques Derrida explains that social reality is constituted by cultural systems (1976:158). More specifically, Derrida asserts that social reality, including dominant historical memory, is constructed within a relational system of production that also actively defers other possible cultural meanings through a process of symbolic violence and marginalization (Game, 1991:17). Social historical reality is both contained in the representational system and moving within its peripheries. Cultural meaning is context-dependent, partial, and the result of struggles over making meaning. Textual analysis, including film-based analyses, is an embodied activity and thus transformational (Barthes, 1977:182). Through a deconstructive methodology I attempt to reveal the highly centralized US social power enmeshed within this cultural artifact and moreover what narratives have been marginalized in the cultural construction of this dominant representation. Irigaray refers to this practice as a method of "jamming the theoretical machinery" (1985:78). She is implying that deconstruction is an embodied activity whereby the social power that has created dominant memory, always haunted and partially constituted by its silenced components, can be exposed. The system of cultural production can be disrupted through critical inquiry (Irigaray, 1985:78). This is a way of unraveling the cultural processes of social silencing that occur during the social construction of collectively held memories. 
operationalize what I mean by "representation" and "social reality", as, my deconstructive analysis reveals the social realities embodied within a representational form. Using the rubric of simulation Jean Baudrillard (1981) explains that within the time period I refer to as hypermodernity, representations are indistinguishable from the real. The implication is that within hypermodernity the real is deeply blurred with the representational form that traces it so that the distinction between the event and the cultural representation decreases. But this is merely appearance. Silenced historical realities, narratives not explicitly encompassed by dominant memory, entangled within the event itself, haunt its commodified expressions. By unraveling this specific representation of Pearl Harbor, the exclusionary violence within the hypermodern representational form, necessarily enacted within a historically specific web of power relations, surfaces.

\section{A Movie that Bombed at the Global Box Office: The Case of Pearl Harbor}

5.1 On December 7th 1941 Japan launched a two-hour "surprise" attack on the United States at Pearl Harbor creating the impetus for US active involvement in World War II. In 2001 Michael Bay directed the blockbuster film Pearl Harbor based on the screenplay by RandallWallace. The film has now been disseminated worldwide through VHS and DVD sales and thus serves as a significant site of remembrance and memory reconstruction for this international event of sixty years before which not only impacted USJapan relations and social life, but also directly effected WWII. In order to understand the mechanisms by which hypermodern collective memory plays out within the realm of popular culture three components of the film need exploration: 1 . the marketing/merchandising, 2. the form, and, 3. the substantive content. Form and content are largely indistinguishable and accordingly these aspects of the film are analyzed in conjunction with one another. It is important to contextualize the movie by beginning with a review of its marketing and associated commodity phenomena; however, first the film's analytical genre must be defined.

5.2 Pearl Harbor can be defined in three ways. Preceding from the specific to the general the possible categorizations are: 1) American films about WWII, 2) American war films, 3) American narrative films with historical subject matter. Pearl Harbor signifies a distinct change in WWII films and war films more broadly because of the film's model (discussed later) and mostly because of the associated commodity phenomenon. The larger change in memory-making, of which Pearl Harbor is a part, is in the form, content and marketing-merchandising of US narrative films with historical subject matter. This broader genre is then the analytical category in which the film is most appropriately located for a sociological reading. Pearl Harbor's place in processes of collective memory is best contextualized by examining it as a part of a larger shift in this broad category of film, that the subject in this instance is war-driven only speaks to (possible) audience consumption but not the larger social process of memory production-distribution.

5.3 Films are normally promoted as original works of cinema. In line with this standard, typically films are not compared to other films as a part of marketing strategy prior to their release. To the contrary, usually film makers and actors abhor the idea that their movie will be perceived as similar to previous films. This kind of comparison seemingly belittles the artistic value of the current film and movie stars often vehemently deny similarities during press junkets. In this way Pearl Harbor is an anomaly. Prior to its US release the stars of the film compared Pearl Harbor to the 1997 film Titanic. Even beyond comparing the dramatic love stories that guide both films and the highly promoted special effects creating "new" images of the past tragedies, the stars of Pearl Harbor asserted that they hoped their film would become the kind of modern-day classic Titanic had been just a few years earlier. Furthermore, they anticipated similar box office success. The film Titanic was the highest grossing film in history so it is not surprising that those in the film industry would hope for a similar success; however, admitting that they followed the Titanic-model in order to try and create a similar audience response remains an unusual publicity strategy. The extraordinary success of Titanic created a model, or format, for narrative films with historical content. The barebones of the model is simple: the narrative is experienced through explicitly fictional characters that intermingle with representations of real-life biographies (the famous/infamous names earlier reduced from the event) and the tragic spectacle is impeccably re-created with sophisticated hypermodern technologies.

\section{Popular Culture and Commodities: Activating Memory for Profit}

6.1 Films exist in the realm of popular culture which is entangled with commercialized leisure: however, the commodity-based phenomenon associated with the release of Pearl Harbor is a direct and traceable aspect of corporate commercial culture. During the marketing campaign surrounding the release of $P$ earl Harbor mainstream bookstores began to display Pearl Harbor books in store windows and on special displays in central locations of stores. This phenomenon has two primary components.

6.2 First, most of the books prominently displayed were written several years to several decades ago. In other words a resurged interest in the event itself does not account for this selling frenzy. Additionally, on past anniversaries of the December 7th attacks this phenomenon did not occur. This is important because it shows that "naturally" occurring national remembrance is also not the cause of the sudden proliferation of 
Pearl Harbor books. In fact, even the tenth, twenty-fifth and fiftieth anniversaries of the event did not cause comparable promotion of Pearl Harbor books as in 2001-- indicating that the film prompted the reemergence of the older books, which, post 9-11 have again found audiences as Pearl Harbor and 9-11 have been constructed as interrelated iconic events (Rosenberg, 2003:B14).

6.3 The second component of this phenomenon is that, to a lesser extent, there was a resurged interest in Pearl Harbor on the part of historians. Several new Pearl Harbor books were published in 2000/2001 including a book consisting solely of reprinted published American newspaper headlines from the weeks following the 1941 event. This heightened interest in researching a historical event of sixty years prior has not occurred within a cultural void. These books were all written and released during the well-known making and marketing of the film Pearl Harbor. After the passing of sixty years an American citizen could go into any chain bookstore in the year 2001 and it would appear as though Pearl Harbor could have happened yesterday. Over a longer period of time and via the Internet this phenomenon has spread throughout other parts of the world. This same phenomenon occurred with the release of Titanic. The activation of collective memory for reconstructive purposes was in this case entirely motivated by profit. This will be further illustrated when discussing how Pearl Harbor was marketed in Japan in order to yield Titanic-like profits in that market, bearing in mind Japan is currently the largest consumer-based for Hollywood films outside of the US and contributed significantly to the overall financial success of Titanic years earlier. In this vein, Buena Vista International, who marketed Pearl Harbor internationally, spent a record ten million dollars to market the film in Japan (James 2001:1;Time, 2001:37). Prior to the US release of the film the head of Disney Studios has calculated zero profits for Japanese box office. Due to the film's disappointing box office gross in the US, the decision was made to edit and heavily market the film in Japan because Japanese audiences typically account for $25 \%$ of the revenue of a Hollywood blockbuster, making Japan the world's second largest box office (Hatfield 2001).

6.4 The commodified textual artifact phenomenon illustrates transformations in the hypermodern experience of time-space. This process also corroborates Hutton's assertion that history is decontextualized and fragmented within media culture. For example, a citizen of virtual America could walk around a shopping mall firmly grounded in the happenings of the new millennium and then pass a bookstore window display and be immediately immersed in 1941 US history regardless of her/his age and experiential knowledge. This immersion in the past is of course partial as the individual can only experience it in relation to the present. This intense transfer to the past is also fleeting as she/he proceeds onwards to encounter technology-based shops such as Sharper Image which are primarily driven by the future-present. The virtual citizen's brush with history-memory is decontextualized and disconnected yet it doesn't seem out of place and generally one does not give it a second thought. This is the experience of history and time when collective memory operates on spatial planes in the realm of commercialized popular culture.

6.5 This commercial phenomenon is also inextricably intertwined with the marketing of Pearl Harbor and the film's well-crafted comparison to the global hit Titanic. After the release of Titanic, once the potential for its ultimate success was clear, an associated commodity campaign was swiftly established. Bookstores began to prominently display Titanic books, most of which were written years before the film's release. Reprinted copies of the New York Times and Boston Globe from the day of the sinking in 1912 were reproduced. These copies were displayed along side current-day newspapers and sold for approximately five dollars per copy. Titanic mementos including figurines, puzzles, games, maps and Titanic inspired jewelry, both costume and gemstone, (replicated from that worn in the film) were widely distributed and rapidly sold. This commodity-based phenomena occurred well after the marketing of Titanic and was the result of its unprecedented audience appeal on a global level. Pearl Harbor is different. This film was intentionally marketed as having a "Titanic feel" in order to (re)create not only box office sales but also resurged public interest in Pearl Harbor memorabilia in the US and eventually globally. Unlike with Titanic, bookstores and publishers did not wait to see the success of the film prior to marketing both new and old Pearl Harbor artifacts.

6.6 When the movie bombed at the box office merchants slowly moved Pearl Harbor books to the reduced bins located to the rear of most bookstore chains. After the events of September 11th Pearl Harbor books were almost completely removed from vision in major bookstores. As a part of a larger research project I had been making bi-weekly visits to two local book chains. This is how I noticed the transfer of Pearl Harbor books post 9-11 although I can not claim a causal relationship. While the terrorist attacks of 9-11 caused a seemingly natural proliferation of mass mediated conversations about the sixty-year old surprise Pearl Harbor attacks (the last large-scale "surprise attack" in the US and "Ground Zero"), this did not (re)create a commodity-based interest in the event. Whether it was the ultimate failure of the film or the events of 9-11 or some combination of both that is responsible for the removal of Pearl Harbor books from prominent sales displays in the US remains empirically inaccessible. It is important to re-member however that when "ground zero" came to mean the site of the fallen World Trade Center Towers as opposed to the memorial at Pearl Harbor, American collective memory regarding Pearl Harbor implicitly changed. Furthermore, 
President Roosevelt's famous response to Pearl Harbor "a date that will live in infamy" now more closely suits the 9-11 surprise attacks as that event has been instantly and repeatedly remembered as a date worldwide, spoken of by President Bush in similar language. The last time this occurred in the American collective was December $7^{\text {th }}, 1941$ and thereby the historical way in which Pearl Harbor has been remembered in the United States has transformed. At this point it is important to note that the commodity form of 9-11 has been growing since the event and by 2004 commodity forms are abundant including September $11^{\text {th }}$ cards (much like American baseball cards), T-shirts, and playing cards picturing "most wanted terrorists." These are only three of the innumerable examples of 9-11 commodities available for purchase worldwide via the Internet (pieces of the fallen towers have even been sold as jewelry). Americanmade documentary films about 9-11 are also plentiful, as well as an international montage film, and the commodity form is ready, worldwide, for linkage to a future dramatic film and the building of a large memory-driven consumer base.

6.7 Beyond marketing, Pearl Harbor was strategically merchandised, a phenomenon that lasted longer than the film creating a larger ultimate "success" than otherwise apparent. In addition to books Pearl Harbor items including hats, pins, posters, CDS, DVDS, videocassettes and so forth continue to be sold. When the key words "Pearl Harbor" are typed into an on-line auction search over 1,200 items typically appear. Not only does this add to the financial success of the otherwise unsuccessful film, but more importantly it shows that the film did bring Pearl Harbor back into active rituals of collective remembering which are a power-laden activity. As discussed in the literature review, while collective memory refers to a shared version of the past, this does not mean it represents a consensus. Foucault (1975) explains that memory is both a political force and a site of opposition. The base-line collective memory typically represents the vision of the dominant group; however, when a repository of memory is "re-activated (IrwinZarecka 1994)," citizens become active in the reconstruction and revision of a memory base. This process has the capability of transforming social power.

\section{The Film's Plot and Characters: Mesmerizing Memories}

7.1 The story of Pearl Harbor is presented through the love triangle of fictional characters Rafe, Evelyn and Danny. Rafe and Danny are childhood friends. The film opens with a scene of the young boys learning the value of loyalty and friendship as Rafe helps Danny escape the wrath of his angry father. A small airplane that the boys desperately long to fly is the source of the turmoil and the main visual focal point of the scene. The boys' love for each other and their dreams of flight are carefully laid out in this opening scene where Rafe acts as Danny's hero-a clear foreshadowing of events to come and an important filming technique within this film genre. The resonant hero-script employed by the media and generally accepted by the American public is immediately established.

7.2 This opening character set-up is built upon expected audience anticipation of later Pearl Harbor battle scenes. This is a critical aspect of cinematic hypermodern memory practices. This short opening scene is the only real character development needed to fulfill the goal of the film which is to (virtually) experience Pearl Harbor through the lives of these two young men. The audience enters the theater expecting to see the story of the American men who fought at Pearl Harbor. The opening scene fosters this anticipation by presenting two young boys who dream of flying airplanes. It is clear that in the next scene(s) we will see these boys as young men, pilots at Pearl Harbor. The relationship between these young men is also important as we can reasonably expect that one of them will die in battle making the "hero" element more profound. This cinematic technique of manufacturing the audiences' emotional response is used in all film genres; however, in the context of historical narratives it has larger implications regarding the reconstruction of memory. The audience can (virtually) experience the grief felt by the survivor. In order to experience the events of sixty-years prior through the eyes of those who lived it, a publicly stated goal of the film, the (already anticipated) grief of the survivor must seem genuine. The boyhood set-up provides this authenticity. This implies that authenticity is gained through the fictional aspects of the film. The film's special effects aimed at creating a "real" account of the battle also exemplify this irony. That the historical content of the film- and global power relations that constitute that content-continues to have political implications is not to be overlooked. The use of fictional heroes helps alleviate any possible contextual responsibility from "real" American individuals or groups. This helps make the film commercially viable, and internationally passable, in a global social context where the US has economic and political relations with Japan.

7.3 The next ninety minutes of the film revolves around the love triangle of Rafe, Evelyn and Danny. Rafe and Danny are now pilots in the military and Evelyn is an army nurse who is ultimately stationed at Pearl Harbor. As noted by film critics, the love-story is clearly a quasi-replication of the love story that guided Titanic four years earlier (Engelhart 2001). This long set up to the highly anticipated attack scenes serves two primary purposes. First, the audience is meant to care about these fictional characters thereby making the ensuing tragedy more emotionally evocative. This is now becoming a fairly common technique used in American produced epoch films with historical content. For example, the first ninety minutes of Titanic, the 
film's model, also follows the love triangle of the guiding fictional characters. This links back to the media's use of resonant hero-scripts, which I argue pave the way for later commercial spins. Irwin-Zarecka (1994) shows that when collective memory is activated there must be central figures which give a "human face" to the event-this connects the audience to the event in an emotional way. As discussed, hero scripts are normative within this practice (Boorstin 1961, 1992; Dayan and Katz 1992). Relations between Japan and the US are radically different than at the time of Pearl Harbor and thus the current economic, technological and political context also mediates this version of the past. For the film to be commercially viable fictional hero figures are created, reminiscent of the kinds of heroes we distantly remember but with the safety of being fictional. This allows the films to be disseminated globally. In the daily Yomiuri Shimbun, Japan's most circulated newspaper, an advertisement read: "The world starts moving; the world is caught in a tide of history. With hope for the future and love in their hearts, young heroes battle against the opposition of the times (French, 2001:3)." Another common Japanese trailer proclaimed: "Pearl Harbor: love story" (James, 2001:1). In order for the film to be viable in Japan in particular, the second largest market for Hollywood films, the fictional hero narrative was a necessary story-telling technique. Arguably without the hero-driven love story the film would not have been released in Japan. The form in which the film's content unraveled, was thus deeply influenced by cross-cultural market imperatives. As the film is a part of citizen's collective memory of the event, this is sociologically significant.

7.4 Returning to the content of the film, second, the audience is introduced to the nurses and officers stationed at Pearl Harbor through following these characters and their friends. This storyline also provides the filmmaker the perfect opportunity to focus on the "fun in the sun" lifestyle these young adults reportedly experienced at Pearl Harbor prior to the attack. This feeds into the element of surprise for those at Pearl Harbor on December seventh much like the public surprise surrounding 9-11. It also fosters heightened audience anticipation- the key element in contemporary collective historical memory. As the audience watches the endless scenes of nurses flirting with army officers on the beaches, a sense of impending doom, based on a standard baseline of Pearl Harbor knowledge, is fortified. In other words, the audience already believes they know what is coming and the ninety minute preface to the attack serves to (re)create anxiety and curiosity. Most interestingly, the preface conjures recollection of past rememberings in conjunction with memories of the not-yet-seen. It is like the song that states: "I remember but it hasn't happened yet (Bjork 1996)." This technique is only possible when the subject of the film is an event, person, or time period that has previously been documented and is therefore taken for granted as part of the collective memory of the target audience.

7.5 The film's climax is the thirty-minute battle scene showing the recreated attack on Pearl Harbor. Several components comprise this key period. The attack was staged as a surprise. Japan had long resisted going to war with the United States but the United States had an oil embargo against Japan. The supply of oil in Japan was dwindling with approximately eighteen months worth remaining. Attacking the US was an effort at ending the oil embargo (Sunshine and Felix, 2001:53). Admiral Yamamoto led the attack at Pearl Harbor. The Japanese military had two main objectives in order to be successful. First, they needed to take the US by surprise. This was viewed as their greatest weapon. Second, their goal was to completely destroy the Pacific Fleet.

7.6 The Japanese military secretly created "The Zero" for this attack. The Zero, a fighter plane, could outperform all other fighter planes at the time. Its lightweight (partly gained through the release of fuel) allowed it to fly higher and faster than other fighter planes. The silver Zeros were marked only with red circles, the symbol of Japan. The Japanese put the same effort into developing torpedoes. They specifically designed torpedoes that were housed in wood boxes. When dropped from the planes into the Pacific the boxes would break off and the torpedoes would travel at high speed in the shallow harbor water. Contributing to audience anxiety and anticipation the first ninety minutes of the film inter-cuts scenes of carefree times at Pearl Harbor with glimpses of the Japanese preparing these vital weapons of war. Reminiscent of newspapers, the dates are shown further heightening audience anticipation which is strategically set against tropical love scenes.

7.7 Armed for battle Admiral Yamamoto knows the US is intercepting Japanese radio signals and launches a surprise attack by sending the US an array of contradictory signals. At the moment of battle the US knows something is about to happen but doesn't know what or where. The dialogue is as follows:

Yamamoto: "Set up teams of radio operators to send out messages the Americans will intercept, concerning every potential target in the Pacific. Include Hawaii- the clutter will be more confusing that way." Genda: " Brilliant, Admiral." Yamamoto: "A brilliant man would find a way not to fight a war." [1]

7.8 This dialogue is a representative example of how the Japanese are portrayed within this film. The filmmaker explicitly stated that he aimed at making a film that dignified the Japanese (Sunshine and Felix, 
2001). First he wanted to show that it was with a heavy heart that they waged war on the US. This contentbased choice can not be removed from the larger social context of power-knowledge relations in which it occurred. At this historical moment Japan and the US are allies enmeshed in a complex web of "global" financial, political and military relations. This current reality deeply mediates this representation in a way that is consistent with dominant political discourse. Second, he wanted to portray them as brilliant strategists. They achieved the element of surprise. Their weapons were unbeatable. And had three US carriers not been out to sea they would have achieved their objective of wiping out the entire Pacific fleet. One must wonder if an American filmmaker closer in time to a traumatic historical event, such as September $11^{\text {th }}$, would aim at dignifying the attackers (or claim to be doing so), and, if as I assume they would not, what are the social and political implications? Furthermore, if the filmmaker dignified the Japanese as promoted in the US, then why was a different version of the film shown in Japan? Furthermore, what does this imply about the social construction of collective memory in a global context? What does this imply about the reconstruction of social historical memory within a commercial, profit-driven context?

7.9 When Pearl Harbor premiered in Japan it did so in the Tokyo Dome, a stadium where the film producers placed a screen the size of a basketball court (French, 2001:3). The dome was filled with 30,000 Japanese viewers (French, 2001:3). But this audience did not see the same film that American audiences saw: they saw a "softer" version of the film with edits, re-shot scenes and voice-overs. This version of the film focused even more heavily on the love story as the film was solely promoted as a love story in Japan (Hatfield 2001). In fact, one author remarked "The billboard image resembles that for Titanic, Japan's highest grosser of all time, and if the ship is smoking rather than sinking, at least its bombed-out glow might be mistaken for a sunset (James, 2001:1)." Many Japanese film goers were dismayed to learn that the film was tailored to specific audiences (French, 2001:3). Moreover, some audience members were troubled by the one-sided nature of the plot and characters. For example, the Japanese pilots were not depicted as having families and relationships and yet the fictional depictions of American soldiers were based on emotional relationships. The larger issue this raises regarding narrating collective memory differently across cultures will be fleshed-out in the conclusion, for now let's return to the film's plot.

\section{Form and Meaning: Constructing Anticipation}

8.1 During the scenes that followed three elements are mixed together creating the key segment of audience anticipation. The uniformed Japanese military are shown preparing for battle. The camera pans the gray-toned images of soldiers standing across the deck of their military base ceremoniously sipping a drink in unison and later in flight heading towards Pearl Harbor. The President and his aides are shown in the President's map room attempting to decipher the cluttered Japanese signals. Evelyn is in Pearl Harbor thinking about her lovers. The weather is beautiful and Pearl Harbor is peaceful. This is also the first moment in the film where characters portraying "real" people (mainly Yamamoto and Roosevelt), and not just fictional characters, are significantly shown.

8.2 The form in which the story plays out is central to the consumption of the substantive content. Film is a unique medium in that it retains its own space-time category innately linked to the use of movement. The experience of space and time is particularly complex in a film with historical subject matter that necessarily builds on a pre-existing repository of collective memory.

"...cinema calls for the subject to project himself into what he sees; it is not presented as evoking a past reality , but as a fiction the subject is in the process of living." (Kristeva, 1989:315)

8.3 Through the use of movement, the foundation of film, the audience virtually experiences Pearl Harbor in the moment. Pearl Harbor complicates notions of time and space within film as the movie both evokes an image of the past and (re)creates a vision of the past with respect to the present. The film is consumed as both history and fiction. The content is (re)presented as Historical while simultaneously the experience of cinema for the viewer is always a fictional journey traveled through the temporary suspension of disbelief. Pearl Harbor helps achieve this audience response by relaying the narrative through explicitly fictional characters. Pearl Harbor uses the common film technique of montage in order to (re)create collective memory. This technique relies on cutting up sequences and structuring them in order to create meaning. By reorganizing the shot into a montage the filmmaker is able to evoke a manipulated signification the shots would not otherwise have (Kristeva, 1989:315). Kristeva explains montage drawing on the work of Eisenstein:

"... a film must be a hieroglyphic text in which each isolated element has meaning only in the contextual combination and according to its place in the structure. " (1989:315-6)

8.4 The use of cinematic montage is the central component to the form of Pearl Harbor. While dramatic music not heard by the actors is commonly used to heighten camera or scene changes during a montage 
(Leavy 1999), and is certainly used in this film, Pearl Harbor also uses starkly different color tones in the three inter-cut plots. Color evokes mood and accordingly this further contrasts the three colliding "realities" presented, fostering audience emotion. This emotion fuels the re-activation of Pearl Harbor memory and is thus complicit in the exercise of social power. Herein is why the reconstruction of collective memory is sociologically significant; relations of social power and dominant and resistive visions of social reality come to the surface through the re-activation of a repository of memory. This is an opportunity for social meanings to be questioned, challenged, and transformed. Furthermore, as Neal (1998) explains, traumatic events often serve as the site for memory practices. This is partly because such events allow later representations to be emotion-driven. By using emotion during the reconstructive process, as is also done by putting a face to an event (Irwin-Zarecka 1994), audiences are more likely to connect with a narrative. This links back to use of events based on thier perceived journalistic and commercial value: traumatic events are more open to emotional narratives, which are more relatable to audiences, and perceived audience response is part of how signature events are selected in the first place. Thus the emotion used in the film Pearl Harbor is significant to how the film is consumed.

8.5 On the morning of December 7th three sub-narratives are cut up to form a sequence aimed at evoking ultimate audience anticipation: 1) shots of the Japanese military ceremoniously preparing for battle 2) shots of the US President and his aides trying to determine what the Japanese are planning, and, 3) shots of a beautiful day at Pearl Harbor. Once the Japanese military has begun their trip to Pearl Harbor shots of the Zeros in flight are inter-cut with the other scenes. Color and sound continue to be exploited furthering the specific montage filming style. Shots of the Japanese are grayed with an emphasis on the silver Zeros. The only bright color seen is the RED of the Zeros and the military uniforms. The President's map room is dark and ominous. Pearl Harbor is shown in bright colors. Each color tone represents the sentiment the filmmaker is purporting as historical and strengthens the hero-villain frame employed in American interpretations of Pearl Harbor since 1941. Music swells with each glimpse of the Japanese. That is precisely what this filming technique gives the audience-a glimpse. The audience is constructed as voyeur to the immanent horror they sit and actively anticipate. An almost secretive fleeting image of the danger that is coming is carefully contrasted with the naîve characters that roam Pearl Harbor as if they need the audience to warn them. The voyeuristic element constructed through cinematic montage transforms the consumption of collective historical memory. The audience is not merely comprised of passive consumers. Rather viewers embody a specific type of (inactive) participation based on anticipation, resurrection and recollection; however, as Lipsitz (1990) reminds us, consumers may think that they are passive because their viewing occurs during leisure time. The same voyeuristic element is present when watching 9-11 documentaries and will be heightened as more commercial films are made. Grainge (2003) drawing on the work of Sklar (1994) notes a shift in film from myth to memory (9). This transition is enabled by the use of anticipation and voyeurism in fictionalized films about real events already deemed significant in a given culture.

8.6 This filming technique continues during the thirty-minute battle scene where shots of the military fight are inter-cut with shots of the nurses caring for the onslaught of wounded officers. The montage style gives way at moments during the battle scene and the technique of "cinematographic narrativity" is employed. This is when a camera-pan is used to present a scene as an uninterrupted sequence (Kristeva, 1989:316). This filming style presents the content as "what is happening" versus "a view on what is happening." The shot takes on a doubled reality effect. The use of this method during the primary scene of audience anticipation is a strategic way of making the premature recollection of what had not yet been experienced now seem as though it were just a recollection of the already experienced. During the height of the movie this style allows the audience to relax and absorb the moving image. After such an elongated period of maximum anticipation, the attack is a strange relief to hyped up consumers. The pan versus the montage is also more 'relaxing' as the eye now follows only one (expected and partially experienced) narrative. The use of this method may appear counter-intuitive but it is highly effective in the (re)formation of dominant collective memory because you feel as the filmmaker wants you to. At this point in the film, anticipation is over but remains the silent foundation of memory reconstruction.

\section{Race and Representation: Reproducing the Dominant Discourse}

9.1 One of the scenes that received disproportionate hype in the US prior to the release of Pearl Harbor is when Dorie Miller grabs a stationary machine gun and fires at the attacking Japanese planes. Miller's character had been briefly contextualized earlier in the film. Miller was stationed at Pearl Harbor on the USS West Virginia where he was the ship's heavyweight boxing champion. As an African-American in a sea of white officers the boxing ring is where he found his freedom. Miller longed to be trained to fight in battle but was instead responsible for tasks such as laundry detail. On December 7th Miller's ship was hit prompting him to go up deck where he carried his wounded captain to safety and eventually manned a machine gun despite his lack of training. Miller later received the Navy Cross for his bravery at Pearl Harbor. His biography has been a mainstay in Pearl Harbor collective memory because he was the only African- 
American of the Pacific fleet to receive such a high honor. What is interesting about the portrayal of Dorie Miller is that he encompasses only minutes of the three-hour film yet he comprises approximately $25 \%$ of the movie trailer time. Undoubtedly more people see the movie trailer than the film and those who see both, anticipate Miller's heroism. Prior to addressing the issue of race and representation in this film, the use of Miller as a central biographic character serves two purposes: 1) event narratives encompass stories with a "human face" so that audiences will emotionally connect (Irwin-Zarecka 1994), and 2) memory-makers use particular frames, such as hero narratives, in order to resonate with audiences (Binder 1993). This said, the more interesting sociological story is the choice of racializing the main hero bio-character in a white-black frame in the context of a cross-national story with a different set of racial issues.

9.2 Pearl Harbor is a highly racialized narrative that has been constructed in a political context of changed modes of racialized power. The use of Miller as a marketing tool, and the placement of his activity within the anticipatory "down-time" of the film, both serve to ease the tensions and contradictions that would otherwise manifest. Specifically, by focusing on the single African-American character as the site of racism/racial conflict, the Japanese and white American racialized depictions that dominate screen time, become consumed as "softer", almost absorbed or distorted by the one Miller scene. Miller is central to the hero narrative in ways that ironically silence questions about racism and the events surrounding Pearl Harbor (notably, the aftermath). It would not be surprising if an American film about 9-11 disproportionately focused on an Arab American civilian killed in the attacks. This speaks to the point of production. As our political-cultural environment has changed since Pearl Harbor, it is now more commercially viable to make space for a discourse about racism through an African-American body set against white racialized representation. This of course is merely a sign of current racism. The "real" story of race however is shown throughout the film via Japanese and white American depictions. This story of race and representation, which again, in terms of time dominates the film, is very much there (materially on the screen), but partially silenced through reverting to the current mainstream image of racism (implicitly racist itself) that American audiences are more accustomed to. Just as journalists choose story-telling frames based on their perceived commercial value (how well they will resonate with audiences), the substantive content of this memory products is also influenced by the kinds of stories the target audience is used to seeing. In other words, the story of race was highlighted as white and black in this film because that is the story of race the majority of the American public is more familiar with. In this film about Japanese and white Americans, race is still about being black. The rigorous marketing of the Dorie Miller scene serves to silence the racial depictions that surround it. Collective memory is used to reinforce dominant notions about race in ways that steer clear of asking questions about American racism towards the Japanese-questions which would challenge the dominant memory.

9.3 A similar choice was made in Titanic where the representative third-class passenger was a white American despite that in real-time Titanic's third-class passengers were an ethnically diverse group of immigrants. Issues of racism implicit within that narrative, and the possibility of an interracial relationship, were silenced through the choice to make that character a white American.

9.4 The remainder of the film focuses on the Doolittle Raid. This was the first US military response to the attack at Pearl Harbor. Again, here the audience is exposed to a blend of "real" people and fictional characters as Rafe and Danny both volunteer for the raid. The use of the Doolittle Raid allows America to end on a note of wartime victory within the confines of the film. This is important to the formation of collective historical memory and the execution of social power. At the end of the movie-day America lost a battle, as anticipated by a knowing audience, but won a war. US response to Pearl Harbor is not shown within the varied forms in which it occurred. For example, the transformations in relations between Japanese-Americans and Caucasian Americans are not explored. Nagasaki is absent from this dominant retelling allowing the final American "win" to appear divorced from future history. But we must remember that the film merely activates dominant American memory. The importance of "how did it end" is further fortified by ending the film with a scene of Rafe and Evelyn happily together years after Pearl Harbor. One might wonder at what point a film about 9-11 would end, and, would America be "up or down" at that point. According to French (2001:3) this issue was not lost among Japanese movie goers who questioned why the movie ignored the reality of Japanese-Americans after the attack, many of whom were ostracized or forced to live in concentration camps, a material marker of institutionalized racism.

\section{Conclusion: Pearl Harbor in a Global Context of Memory Activation}

10.1 Pearl Harbor can be broken down into three main time-space experiences: 1) the first ninety minutes is driven by anticipation and the simulated recollection of the not yet seen in conjunction with the already "remembered", 2) the thirty minute battle scene fosters a counter-intuitive relaxation and absorption of this (k)new narrative, and, 3) the last sixty minutes serves to remind the audience that the US never loses even when they do not win, and ultimately this is just a fictional love story. The content is reinforced as fragmented, disconnected, and decontextualized from the complex power relations of a time that, once 
10.2 What does this analysis tell us about the larger history-memory-popular culture nexus? Within hypermodernity the construction of American collective historical memory is based on consumer anticipation. Artifacts of memory build upon those that came before. Each new representation is consumed in relation to a pre-existing baseline of collective memory. This creates a unique phenomenon where consumers of commercialized collective memory participate in the reconstruction of collective memory through heightened anticipation. What they expect but have not yet seen, is experienced as if it were already personally witnessed. At the moment of consumption the representation thus takes on a built-in level of authenticity that is merely an illusion. This has the potential to reinforce dominant discourse without paying proper attention to the exclusionary violence that characterizes the narrative.

10.3 It is important to note that the systematic use of "anticipation" in films about historical events differs for events that didn't quite happen. In films about events that did occur, such as Pearl Harbor, Titanic, and 911, the audience knows in advance what the climax of the film will be. Other American films about historical events, whose social importance lie in what did not happen, present a different experience for the viewer. For example, Apollo 13 (about the American space shuttle that almost met disaster) and Thirteen Days 1999 (about the Cuban Missile Crisis which did not result in a nuclear war) do not rely on the same methods of reconstructed anticipation. The audience does not have a preconceived "memory" of the film's not-yet-seen climax, because, since the event was a non-event, the dramatic climax is somewhat unknown until it unfolds. The different filming strategy and audience experience is itself clarified in an early line from the film Thirteen Days when President Kennedy's political advisor is informed of Soviet missiles in Cuba: "Jesus. I feel like we caught the Jap carrier heading for Pearl Harbor." Differing from the Pearl Harbor experience, the audience spends the rest of the film wondering how a crisis will be prevented and not anticipating the spectacle of a crisis. The same is true in Apollo 13 after the famous line: "Huston, we have a problem."

10.4 Due to the particulars of audio-visual narratives, film is the medium which best suits the anticipatory technique of memory-making. Television programs differ in that they project diffuse representations whereas a film is a self-contained representation with the capacity to spin a cogent dominant narrative, or, a completely resistive and even counter-hegemonic narrative. Films are also the textual form most likely to be accompanied by an associated commodity phenomenon. The marketing of American films already occurs within the locus of global advertising- the mass media. Creating resurged interest in a historical topic of national remembrance can be used to create interest not only in the film itself but also in associated products. These products then bear traces of the film as if it were the event. Moreover, the commodities, as the film, re-activate a repository of collective memory centered on a particular event, a repository that may otherwise have been dormant. This is evidenced by comparing Pearl Harbor with the highly successful film Titanic. While the movies commandeered different financial rewards and critical praise, both re-opened an event's ritual memory construction post real-time. Why Titanic was successful as a film and Pearl Harbor wasn't, is less important than their ultimate impact on hypermodern processes of cultural remembering. The extent to which consumers may choose to engage in remembering Titanic, an industry accident, versus Pearl Harbor, a battle situated within a larger war and complex web of racialized and militarized social power, can not be underestimated. This is particularly true for its global audience post 9-11. In the end, both films successfully re-activated dominant memory practices regarding each event bringing their collective memory(s) into the forefront of the history-memory-popular culture nexus. As Hollywood films are now distributed nearly worldwide, there are even larger implications for the cultivation of this nexus.

10.5 When comparing the marketing and content of the film in the US and Japan two interrelated phenomena arise: 1 ) tailoring representations of collective memory to suit audiences, and 2) the power of the hero-villain script in commercially produced artifacts of collective memory. These two issues are both are a part of the commercial imperative that drives collective memory in the media age. The modifications made to the film for Japanese audiences illustrate the way that memory-makers gear representations to the audience in order to increase profits. This also illustrates Sturken's (1997) contention that cultural memory is a site of negotiation that is linked to national identity formation. Because the film makers purported this film to be an "accurate" representation this cross-cultural analysis raises socially significant questions about any authenticity claims in a commercial context. The reactions of Japanese viewers also indicate the importance of the narrative frame in the reconstruction of collective memory. While both audience members and government officials reported being troubled by the one-sided American view in the film (French, 2001:3), many filmgoers also focused on the love story and hero narrative and thus had a more nuanced response to the film (at once patriotic and empathetic). One thirteen year old viewer said: "I was moved to tears at the point when Danny died (French, 2001:3)." Many Japanese consumers relayed similar experiences indicating that the framework through which the story was told deeply impacted how people perceived the content. In this way the hero-script was vital to the consumption of this representation. Furthermore, the lack of public protest or resistance to the film in Japan, as was expected, raises 
questions about why citizens were largely indifferent or apathetic to the film. It is possible that marketing the film as a love story also freed the film from more scrutiny on the grounds of historical accuracy.

10.6 As Pearl Harbor reaches additional global audiences through cinema showings and DVD and VHS sales, citizens of the world are participating in the reconstruction of an American-centered version of an international event, but in a complex way. Furthermore, global audiences are becoming familiar with the kind of scripts put forth by American memory-makers, scripts that rely on hero/villain dichotomies. Empirical research is needed to examine how different audiences consume narratives such as this. This said, one could assume that, given a different set of cultural understandings and familiarity with different cultural frames and referent images, different audiences might consume the film in distinct ways.

Comparing across various cultures is important as well. For example, Japanese audiences have also been exposed to a base-line collective memory of Pearl Harbor; however, this memory has been narrated from a different perspective as evidenced by Japan's reaction to the film, and particularly, its omissions.

Additionally, young people in Japan may know considerably less about Pearl Harbor than one might think. Japan has "suppressed its domestic history" in this regard and school books gloss over Pearl Harbor while Japanese filmmakers stay away from the subject (Hatfield, 2001:1;James, 2001:2). Some Japanese teenagers have never learned about Pearl Harbor. Since young people were the film's target audience, this film may act as an important part of base-line collective memory for young Japanese audience members. Many young moviegoers reported hoping to learn something through the film (French, 2001:2) acknowledging the "educational" aspect of consuming this narrative. This raises a sociologically significant question: What does it mean for a new generation of Japanese citizens to learn about Pearl Harbor through an American fictionalized representation constructed with profit in mind?

10.7 This film didn't only reactivate social memory processes in the US and Japan. The film was released and later sold throughout the world and after the worldwide premiere week, Germany had the best box office returns for the film despite its third position in the weekly rankings while it initially premiered in the top slot in Japan (Groves, 2001). Citizens throughout the world, all with different relations to WWII and different cultural backdrops, may also consume the film differently. This is not to say that some aspects of the film and the collective memory it revisits are not the same across cultures, but rather implies that global audiences might have a hybridized response to the film, sharing some aspects of the script with American audiences and differing in other areas, thereby creating a different, hybridized, consumptive experience. All of this requires further research.

\section{Acknowledgements}

My gratitude to Stephen Pfohl for his many readings of this and related writing and his in-depth, provocative, and important feedback. Thanks to Stonehill students Paul Sacco, Michael Gennaro and Cheryl Llewellyn for their help with the lit review. And thank you to the anonymous reviewers whose comments have helped enormously with this work.

\section{Notes}

1 This dialogue is quoted from Sunshine and Felix, 2001.

\section{References}

APOLLO 13 (1995) New Line Studios (VHS).

BAUDRILLARD, Jean. (1981 and 1999) Simulacra and Simulation. The University of Michigan Press

BARTHES, Roland. (1977) "Rhetoric of the Image" in Image, Music, Text, Stephen Heath, tr. New York: Hill and Wang. BINDER, Amy (1993). "Constructing Racial Rhetoric: Media Depictions of Harm in Heavy Metal and Rap Music" in American Sociological Review.

BJORK, (1996) "I Miss You" from Post (audio CD)

BOORSTIN, Daniel J. $(1961,1992)$ The Image: A Guide to Pseudo-Events in America. Vintage Books:

CRUZ, Consuela (2000). "Identity and Persuasion: How Nations Remember Their Pasts and Make Their Futures" in World Politics.

DAYAN AND KATZ. (1992) Media Events: The Live Broadcasting of History . Harvard University Press. 
DERRIDA, Jacques. (1976) Of Grammatology; translated by Gayatri Spivak. Johns Hopkins University Press

ENGELHART, Mark. (2001) "Review of Pearl Harbor Theatrical Release" http://www.amazon.com. FOUCAULT, Michel. (1978) The History of Sexuality: An Introduction Volume 1. Vintage Books FOUCAULT, Michel (1975). "Film and Popular Memory" in Radical Philosophy.

FRENCH, Howard W. "'Pearl Harbor' in Japan: Love or War?" In The New York Times. June 22, 2001. Section A, Column 1, p. 3.

GAME, Anne. (1991)Undoing the Social: Towards a Deconstructive Sociology.

GAMSON, Bill and Modigliani, Andre. (1989) "Media Discourse and Public Opinion on Nuclear Power: A Constructionist Approach" In American Journal of Sociology.

GRAINGE, Paul (Ed.). (2003) Memory and Popular Film . Manchester University Press.

GROVES, Don. "'Pearl Harbor' Scores Japan Hit" in Variety, July 23, 2001 \383 i9 p13.

HATFIELD, Peter (2001). "Japan's Date with Pearl Harbor" in BBC News on-line. June 21, 2001

Entertainment Section.

HOSKINS, Andrew (2004). "Television and the Collapse of Memory" in Time \& Society.

HUTTON, Patrick H. (1993) History as an Art of Memory . University Press of New England.

IRIGARAY, Luce. (1985) This Sex Which Is Not One. Cornell University Press.

IRWIN-ZARECKA, Iwona. (1994) Frames of Remembrance: The Dynamics of Collective Memory Transaction Publishers.

JAMES, Victoria. "Japan Snores Through Pearl Harbor: Critical Essay" in New Statesman on-line, July 23, 2001.

KRISTEVA, Julia. (1989) Language the Unknown: An Initiation into Linguistics. Columbia University Press.

LEAVY, Patricia. (1999) "Studying Postmodernism Using Film: The Music the Actors Can Not Hear". Paper Presented at the Popular Culture Association and American Culture Association Joint Conference, San Diego

LIPSITZ, George. (1990) Time Passages: Collective Memory and American Popular Culture. University of Minnesota Press.

NEAL, Arthur G. (1998) National Trauma \& Collective Memory: Major Events in the American Century . M. E. Sharp.

PEARL HARBOR (2001) Walt Disney Home Video (VHS).

READING, Anna. (2002) The Social Inheritance of the Holocaust: Gender, Culture and Memory. Palgrave Macmillan.

ROSENBERG, Emily S. (2003). "September 11: Through the Prism of Pearl Harbor" in The Chronicle of Higher Education.

ROSENWEIG, R. and Thelen, D. (1999). Extract from 'The Presence of the Past: Popular Uses of History in American Life', Humanities: When Stones Speak: Communicating Across the Ages, Special Issue, January/February, vol. 20 no. 1, 15-16.

SCHUDSON, Michael. (1992) Watergate in American Memory: How we Remember, Forget, and Reconstruct The Past. Basic Books.

SKLAR, Robert. (1994) Movie-Made America: A Cultural History of American Movies. New York: Vintage Books.

SONTAG, Susan. (2003) Regarding the Pain of Others . Farrar, Straus and Giroux. 
STURKEN, Marita (Ed.). (1997) Tangled Memories: The Vietnam War, The AIDS Epidemic, and The Politics of Remembering. University of California Press.

SUNSHINE, Linda and Antonia Felix (Eds.). (2001) Pearl Harbor: The Movie and the Moment. Disney Enterprises.

THIRTEEN DAYS (2001) New Line Studios (VHS).

TIME. "A Kinder, Softer Movie: Disney hopes to sell Japan a revised Pearl Harbor." July 2, 2001. v157, i26, p.37.

TITANIC (1997) Paramount Studios (VHS).

WALLACE, Randall (2000) (screenplay) Pearl Harbor.

ZELIZER, Barbie. (1992) Covering the Body: The Kennedy Assassination, The Media, and the Shaping of Collective Memory. University of Chicago Press. 